\title{
EFFECT OF DOMINANCE ON THE ISOMETRIC HAMSTRING MUSCLE STRENGTH IN UNDERGRADUATE STUDENTS
}

\author{
OO Oyewole \\ Department of physiotherapy, Olabisi Onabanjo University Teaching Hospital, \\ Sagamu.
}

\begin{abstract}
Background: The knee is frequently prone to traumatic and degenerative afflictions and hence is a common site of pain requiring physical therapy interventions. During the process of rehabilitation, comparisons are usually made with the contralateral knee vis-à-vis the knee muscle torques as a criterion reference. In order to validate this practice, is necessary to determine to what extent a pre-injury difference exists between the limbs of otherwise normal subjects.
\end{abstract}

Objective: The purpose of this study was to provide isometric strength data of hamstring muscles in healthy subject and to investigate the effect of dominance on it.

Method: Eighty normal male undergraduate subjects with mean age of $23.5 \pm 2$.14years (range 20-29) were exposed to isometric muscular strength measurement of the hamstring muscles. The thigh muscle bulk, limb length and leg length were also measured.

Results: The result showed that dominance has effect on the isometric muscular strength of the lower limb when classified as dominant or nondominant, strong or weak and right or left. There was also significant effect of dominance on muscle bulk. Significant correlation was found between muscle strength, muscle bulk and body weight. No correlation was found between muscle strength and leg length. Age has no effect on the strength.

Conclusion: This study suggests that in gross comparisons only, pre-injury significance exists between contralateral limbs.

KEYWORDS: Isometric hamstring muscle strength, dominance leg, leg length, muscle bulk.

\section{INTRODUCTION}

The hamstring muscle group is one of the most complex sets of muscles in the body, intricately involved in both locomotion and stability of the lower extremity (Coole and Greck, 1987). The knee is frequently prone to traumatic and degenerative afflictions and hence is a common site of pain requiring physical therapy interventions. During the process of rehabilitation, comparisons are usually made with the contralateral knee vis-àvis the knee muscle torques as a criterion reference (Onuoha, 1990). In order to validate this practice, is necessary to determine to what extent a preinjury difference exists between the limbs of otherwise normal subjects. Any appreciable differences present would raise serious doubts over this widely used practice. In sports, adequate knowledge of muscle strength is required. Especially that of hamstring muscle because of its function in locomotion and stability (Coole and Greck, 1987).

Previous works done on the effect of dominance on muscle strength of various muscle groups have been reporting contradictory reports. Some studies found no significant difference between dominant and non-dominant legs (Onuoha, 1990; Calmels et al, 1997; Demura et al, 2001; Nadler et al, 2002; Magalhaes et al, 2004; Zakas, 2006; McCurdy and Langford, 2006). While other studies have reported significant differences between the strength of dominant and non-dominant legs (Knapik et al, 1991; Hunter et al, 2000; Ford et al, 2003; Jacobs and Mattacola, 2004; Ergun et al, 2004; Jacobs et al, 2005). Therefore, the purpose of this study was: 1) to provide clinicians, exercise physiologist and sports physiologist with descriptive data on the isometric strength of hamstring muscle, 2) to find the effect of dominance on hamstring muscle strength and muscle bulk, 3) to find correlation between hamstring muscle strength and muscle bulk, and 4) to find the effect of age on hamstring muscle strength.

\section{METHODS Subjects}

Participants for this study consisted of a convenience sample of 80 healthy male undergraduates of Obafemi Awolowo University (OAU), with no history of chronic or acute musculoskeletal injury of both lower limbs. The average age was 23.58 \pm 2.14 years (range 20-29 yrs); height $1.72 \pm 0.06 \mathrm{M}$ (range 1.59-1.94 M) and weight $61.74 \pm 7.81 \mathrm{Kg}$ (range $47-86 \mathrm{Kg}$ ).

Instrumentation: a cable tensiometer calibrated in kilogram (range 0 - $150 \mathrm{Kg}$ ) and stadiometer (Seca, Prazision Furdic Gesundheit, Germany) were used to measure the strength of the hamstring muscle group and height respectively. Bathroom scale and tape rule were also used to measure weight, thigh muscle and segmental limb lengths respectively. 
Procedure: on the arrival of the participants at the testing site (Kinesiology laboratory of the department of medical rehabilitation, OAU, IleIfe), the procedure were explained to them and their physical characteristics were measured and recorded. Prior to measurement the following questions were asked: 1) which limb is mostly used or which leg will be preferred in kicking a ball when playing a football to ascertain dominant leg (Onuoha, 1990; Jacobs et al,2005), 2) any case of injury or fracture to the lower limb? The participants with history of injury or fracture to their lower limbs were excluded.

Thereafter, limb lengths and thigh muscle bulk were measured in standing position. The limb length and thigh length were measured from coccyx to the floor and from coccyx to the central axis (popliteal fossa) of the knee respectively. The muscle bulk was measured immediately below the gluteal fold. The participants proceeded to lie prone on a plinth with their lower limbs extended beyond the edge of the testing table in order to measure hamstring strength. An ankle cuff was placed round their ankles and attached to the cable tensiometer which was finally attached by a hook at its other end to a wooden bar between the testing table legs. A strap was used to strap their buttock to the testing table in order to keep the hip flexion angle at $0^{\circ}$. They were instructed to flex their knees maximally at the shout of 'pull' after the count of 3 . The readings were taken when the reading pointer was sustained. Two readings were taken in which the highest values were used in computation. The hamstring muscle strength of both limbs was measured one after the other.

Data Analysis: descriptive statistics of range, mean, and standard deviation were used to analyze the age, weight and height of the participants. Paired $t$ test was used to determine if there were significant differences between hamstring muscle strength and muscle bulk of dominant and non-dominant limbs. Pearson product correlation was used to determine if there were significant correlations between muscle bulk, leg length, body weight and hamstring strength. A $5 \%$ level of significance was set for all tests.

\section{RESULTS}

The physical characteristics of the subjects are shown in table 1 . Paired t- test showed significant difference at $5 \%$ level of significance when the limb strength was classified as dominant and non-dominant, weak and strong, right and left (tables 2, 3 \& 4).The dominant, strong and right limb strengths were significantly higher than the non-dominant, weak and left limb strength respectively. Paired t-test also revealed significant difference between the muscle bulk of dominant and non-dominant limbs (table2). Dominant limb muscle was significantly higher than non-dominant muscle bulk.

Tables 5 and 6 present Pearson correlation between muscle strength, muscle bulk, leg length and body weight for dominant and non-dominant limbs. There were significant correlations between muscle strength, muscle bulk and body weight for both dominant and non-dominant limbs. No correlation was found between muscle strength and leg length. Table 7 presents effect of age on strength. No significant difference was found between the 2 age groups when classified into two i.e. 20-24years and 25-29 years respectively.

Table 1: Subjects' physical characteristics $(n=80)$.

\begin{tabular}{lll}
\hline Variables & Range & Mean \pm SD \\
\hline Age (yrs) & $20-29$ & $23.58 \pm 2.14$ \\
Weight $(\mathrm{Kg})$ & $47-86$ & $61.74 \pm 7.81$ \\
Height $(\mathrm{cm})$ & $159-194$ & $172.2 \pm 6.1$ \\
\hline
\end{tabular}

Table2: Comparison of muscle strength and muscle bulk between dominant and non-dominant limbs $(n=80)$.

\begin{tabular}{|c|c|c|c|c|}
\hline \multirow[t]{2}{*}{ Variables } & \multirow{2}{*}{$\begin{array}{l}\text { Dominant limb } \\
\mathrm{X} \pm \text { SD }\end{array}$} & \multicolumn{2}{|c|}{ Non-dominant limb } & \multirow[b]{2}{*}{$\mathbf{P}$} \\
\hline & & $\mathrm{X} \pm \mathrm{SD}$ & $\mathbf{T}$ & \\
\hline Muscle strength (Kg) & $27.11 \pm 6.06$ & $25.78 \pm 6.33$ & 4.880 & .05 \\
\hline Muscle bulk (cm) & $51.66 \pm 3.95$ & $51.20 \pm 3.92$ & 4.323 & .05 \\
\hline
\end{tabular}

Table 3: Comparison of muscle strength between strong and weak limbs $(\mathrm{n}=80)$.

\begin{tabular}{lllll}
\hline Variables & $\begin{array}{l}\text { Strong limb } \\
\text { X } \pm \text { SD }\end{array}$ & $\begin{array}{l}\text { Weak limb } \\
\text { X } \pm \text { SD }\end{array}$ & T & P \\
\hline Muscle strength (Kg) & $27.50 \pm 6.21$ & $25.39 \pm 6.06$ & 10.05 & .05 \\
\hline
\end{tabular}


Table 4: Comparison of muscle strength between right and left limbs $(n=80)$.

\begin{tabular}{lllll}
\hline Variables & $\begin{array}{l}\text { Strong limb } \\
\mathbf{X} \pm \text { SD }\end{array}$ & $\begin{array}{l}\text { Weak limb } \\
\text { X } \pm \text { SD }\end{array}$ & t & P \\
\hline Muscle strength $(\mathrm{Kg})$ & $27.04 \pm 6.03$ & $25.85 \pm 6.37$ & 3.839 & .05 \\
\hline
\end{tabular}

Table 5: Correlation co-efficient between dominant strength, dominant bulk, leg length and body weight $(n=80)$.

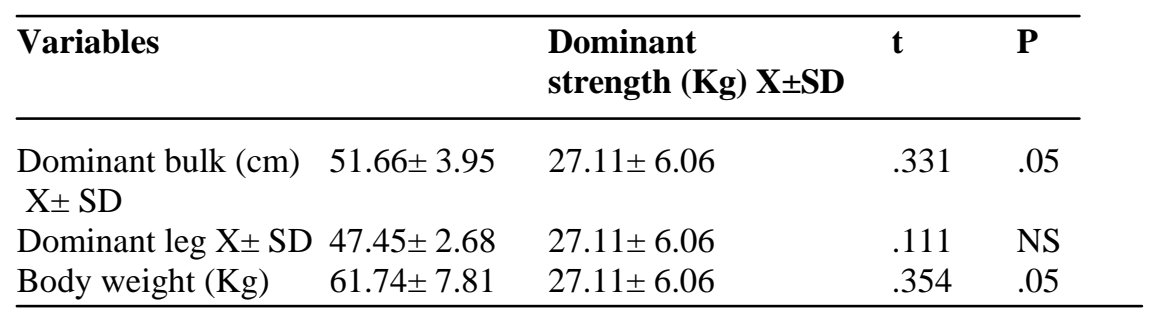

Table 6: Correlation co-efficient between non-dominant strength, non-dominant bulk, leg length and body weight $(n=80)$.

\begin{tabular}{|c|c|c|c|c|}
\hline Variables & & $\begin{array}{l}\text { Dominant } \\
\text { strength }(\mathrm{Kg}) \mathrm{X} \pm \mathrm{SD}\end{array}$ & $\mathbf{t}$ & $\mathbf{P}$ \\
\hline $\begin{array}{l}\text { Dominant bulk (cm) } \\
\text { X土 SD }\end{array}$ & $51.66 \pm 3.95$ & $27.11 \pm 6.06$ & .331 & .05 \\
\hline Dominant leg $\mathrm{X} \pm \mathrm{SD}$ & $47.45 \pm 2.68$ & $27.11 \pm 6.06$ & .111 & NS \\
\hline Body weight (Kg) & $61.74 \pm 7.81$ & $27.11 \pm 6.06$ & .354 & .05 \\
\hline
\end{tabular}

Table 7: Effect of age on muscle strength.

\begin{tabular}{lllll}
\hline Variables & $\begin{array}{l}\mathbf{( N = 5 6 )} \\
\text { Age 20-24yrs } \\
\text { X } \pm \text { SD }\end{array}$ & $\begin{array}{l}\mathbf{( n = 2 4 )} \\
\text { Age 25-29yrs } \\
\mathbf{X} \pm \text { SD }\end{array}$ & t & P \\
\hline Muscle strength $(\mathrm{Kg})$ & $26.25 \pm 6.64$ & $27.50 \pm 4.50$ & -0.369 & NS \\
\hline
\end{tabular}

\section{DISCUSSION}

The purpose of this study was to provide physical therapist, Exercise physiologist and sport physiologist with isometric strength data of hamstring muscles on healthy college age students. The results of the present study revealed significant difference between peak strength using cable Tensiometer of the limbs when categorized as right or left, dominant or non-dominant and strong or weak. In other words, there was significant difference in the peak strength of the right versus the left limb of the subjects. This findings is consistent with those reported by Knapik et al, 1991; Hunter et al, 2000; Ford et al, 2003; Jacobs and Mattacola, 2004; Ergun et al, 2004; and Jacobs et al, 2005. In contrast, Onuoha, 1990; Calmels et al, 1997; Demura et al, 2001; Nadler et al, 2002; Magalhaes et al, 2004; Zakas, 2006; McCurdy and Langford, 2006 found no significant difference in the peak strength of dominant and non-dominant limbs, but Onuoha found significant difference when classified strength as strong or weak. The reasons for the discrepancies between data from this study and the other studies are not readily apparent. These differences, however, may reflect the sample size in this investigation related to other study (Jacobs et al, 2005). Those that found significant difference were those that used larger sample sizes.

The discrepancies may also result from definition of dominance by various authors. Some researchers define it as the leg preferred for kicking (Onuoha, 1990 and Jacobs et al, 2005). Some use questionnaire to determine dominance (Demura et al, 2001). And some do not specify how dominance should be established to make future findings meaningful.

The findings of this study suggest that the usual practice in rehabilitation of using unaffected limb as a criterion reference in building up the strength of the affected limb or bi-lateral comparisons as parameters for discharging patients from rehabilitation programmes can be misleading.

This study found significant difference between muscle bulk of the dominant and non- 
dominant limbs. This might be as a result of frequent use of dominant limb thus causing hyper-trophy. Significant correlation was found between muscle bulk and muscle strength for both dominant and non-dominant limbs. These findings found no significant correlation between muscle strength and leg length. The leg length serves as a lever arm or moment arm or perpendicular distance from the line of application of the musculotendinous unit to the axis of rotation for the joint. Gary and Rogers (1982) has shown that moment arm has influence factor on muscle strength. Further study should be done in future varying the moment arm.

Significant correlation was found between body weight and muscle strength for both limbs. This finding was in consistency with that of Holmes and Aderink (1984), and Aniansson etal (1980). This study fond no significant difference between the muscle strength of the two age groups. This was consistent with that of Holmes and Aldernik (1984), and Kauffman (1985). This finding was in contrast with other findings (Murray etal, 1980). The result of this present finding might be due to closeness of the two age groups. It has been shown that there is a rapid increase in strength before the age of 19, with a slower increase up to 30 years of age. From 30 years until 60 years of age, strength decreases at an increase rate (Hunter et al, 2000).

\section{CONCLUSION}

The results of this study highlighted the fact that dominance has effect on the muscular strength of the lower limb extremities with regards to the hamstrings muscle. Significant difference was also found when classified strength as strong and weak or right and left. Dominance has effect on muscle bulk. Correlation was found between muscle bulk and strength. Total body weight has correlation with peak strength.

\section{Clinical Implication}

This study suggests that in gross comparisons only, pre-injury significance exists between contralateral limbs. Therefore, the bilateral comparisons made between the 2 limbs, with one as the affected limb and the other as non-affected may not be justified and should not be employed as valid criterion measure for exercise progression.

\section{REFERENCES}

- Aniansson A, Grimby G and Reindgren A (1990): Isometric and isokinetic quadriceps muscle strength in 70 year old men and women. Scandinavia Journal of Rehabilitation Medicine. 12: $161-168$.
- Calmels P.M, Mellen M.N, van der Borne I, Jourdin $P$ and Minaire P (1997): Concentric and eccentric isokinetic assessment of flexor-extensor torque ratios at the hip, knee, and ankle in a sample population of healthy subjects. Archieve of Physical Medicine and Rehabilitation 78: 1224-1230.

- Coole W.G and Gieck J.H (1987): An Analysis of hamstring strains and their rehabilitation. The Journal of Orthopedic and Sport Physical Therapy 9(2): 77-85.

- Demura S, Yamaji S, Goshi F and Nagasawa Y (2001): Lateral dominance of legs in maximal muscle power, muscular endurance, and grading ability. Perceptual and Motor Skills 93(1): 11-23.

- Ergun M, Islegen C and Taskiran E (2004): A cross-sectional analysis of sagittal knee laxity and isokinetic muscle strength in soccer players. International Journal of Sports Medicine 25(8): 594-8 .

- Ford K.R, Myer G.D and Hewett T.E (2003): Valgus knee motion during landing in high school female and male basketball players. Medical Science and Sports Exercise 35: 1745-1750.

- Gary L.S and Rogers M.W (1982): Factor contributing to the regulation and clinical assessment of muscular strength. Physical Therapy 62: 1283-1289.

- Holmes J.R and Aldernik G.J (1984): Isokinetic strength characteristics of the quadriceps femoris and Hamstrings muscles in high school students. Physical therapy 64: 914-918.

- Hunter S.K, Thompson M.W and Adams R.D (2000): Relationships among age-associated strength changes and physical activity level, limb dominance, and muscle group in women. Journal of Gerontology. Series A, Biological Sciences and Medical Sciences. 55(6): B264-73 .

- Jacobs C, Uhl T.L, Seeley M, Sterling W, and Goodrich L (2005): Strength and Fatigability of the Dominant and Nondominant Hip Abductors. Journal of Athletic Training 40(3): 203-206.

- Mattacola C.G (2004): Eccentric hip strength and kinematic differences between the dominant and non-dominant legs of men and women during a hopping task. Journal of Athletic Training 39: S34-S-35. (suppl).

- Knapik J.J, Bauman C.L, Jones B.H, Harris J.M and Vaughan L (1991): Preseason strength and flexibility imbalances associated with athletic injuries in female collegiate athletes. American Journal of Sports Medicine 19: 76-81.

- Magalhaes J, Oliveira J, Ascensao A and Soares J (2004): Concentric quadriceps and hamstrings isokinetic strength in volleyball and soccer players. Journal of Sports Medicine and Physical Fitness 44(2): 119-25. 
- McCurdy K and Langford G (2006): The relationship between maximum unilateral squat strength and balance in young adult men and women. Journal of Sports Science and Medicine 5: $282-288$.

- Murray M.P, Gardner G.M, Mollinger L.A and Sepic S.B (1980): Strength of isometric and isokinetic contractions. Physical Therapy 60: 412-19.

- Nadler S.F, Malanga G.A, Bartoli L.A, Feinberg J.H, Prybicien M and Deprince M (2002): Hip muscle imbalance and low back pain in athletes: influence of core strengthening. Medical Science and Sports Exercise 34: 9-16.

- Onuoha A.R (1990): Comparison of quadriceps and hamstring functions in college-age students. Physiotherapy 76(3): 172-76.

- Zakas A (2006): Bilateral isokinetic peak torque of quadriceps and hamstring muscles in professional soccer players with dominance on one or both two sides. Journal of Sports Medicine and Physical Fitness 46(1): 28-35. 